\title{
DISCURSO E IDEOLOGIA: ANÁLISE CRÍTICA DE TEXTOS DIDÁTICOS PARA O ENSINO DE INGLÊS
}

\author{
(Discourse and Ideology: critical analysis of didactic text for \\ English teaching)
}

José Roberto Alves Barbosa ${ }^{1}$

\begin{abstract}
Didactic texts have been widely used for English teaching at institutionalized contexts. We aim, with this paper, at analyzing critically didactic texts used for English Teaching at High Schools, but those texts are not critically analyzed by English teachers and students involved in the teaching and learning process. Based on this reality, we intend, with this paper, to analyze critically some didactic texts used for English teaching in High School contexts. This paper is based on Critical Discourse Analysis, by Fairclough (2003), and to analyze images, on Grammar of Visual Design, by Kress and van Leeuwen (2006).
\end{abstract} Keywords: texts, critical, teaching, English.

\section{RESUMO}

A utilização de textos didáticos para o ensino de inglês tem sido prática recorrente em contextos institucionalizados, mas nem sempre esses textos são analisados criticamente por professores e alunos envolvidos no processo. Diante dessa realidade, propomos, através deste artigo, uma análise crítica de textos didáticos para o ensino de inglês no Ensino Médio. Para tanto, partimos dos pressupostos teóricos da Análise de Discurso Crítica (ADC), de Fairclough (2003), e para a análise das imagens nos mesmos textos, nos baseamos na Gramática do Design Visual, de Kress e van Leeuwen (2006). Palavras-chave: textos, crítica, ensino, inglês.

1. Professor do Departamento de Letras Estrangeiras da Universidade do Estado do Rio Grande do Norte (UERN), líder do Grupo de Pesquisa em Lingüística e Literatura (GPELL), mestre em Lingüística Aplicada pela UFRN e doutor em Lingüística pela UFC. Desenvolve pesquisas na área de Ensino Crítico de Línguas. É líder do Grupo de Pesquisa em Lingüística e Literatura da UERN e membro do Grupo de Estudo de Discurso, Identidade e Prática Social, da UFC. 


\section{Considerações iniciais}

A língua inglesa tornou-se um produto de consumo (Lacoste \& Rajagopalan, 2005), tornando-se objeto de desejo social. O interesse por essa língua, entre outros motivos, decorre da difusão global que obteve nessas últimas décadas. Diante de tal expansão, o mercado editorial tem produzido vários recursos didáticos a fim de possibilitar o contato dos alunos com o idioma. Alguns textos, no entanto, não favorecem apenas o acesso à língua, mas também às práticas discursivas ideologicamente construídas (Thomspon, 1995). Este artigo pretende analisar textos didáticos para o ensinoaprendizagem de inglês no Ensino Médio de escolas particulares. Na primeira parte discorreremos sobre a situação atual do inglês no mundo e a mercantilização do seu ensino, em seguida, trataremos a respeito dos aspectos teórico-metodológicos da Análise Crítica do Discurso (ADC, com base em Fairclough (2001; 2003), também denominada de Análise de Discurso Textualmente Orientada (ADTO) e Gramática Visual (GV), de Kress e Van Leeuwen (2006). $\mathrm{Na}$ segunda parte do artigo, desenvolveremos a análise, atentando para os aspectos genéricos, discursivos, identitários e imagísticos dos textos didáticos.

\section{A difusão mundial do inglês}

O interesse por essa língua decorre da ampla difusão global que esta obteve nessas últimas décadas (Rajagopalan, 2003; Lacoste \& Rajagopalan, 2005). Diante de tal expansão, o mercado editorial tem produzido vários livros didáticos a fim de que os alunos tenham contato com a língua. Mas esses textos não apenas possibilitam o acesso à língua, mas também às práticas discursivas hegemônicas e ideologicamente construídas (Thomspon, 1995). Para a fundamentação teórica da pesquisa, partiremos das contribuições da Análise de Discurso Crítica (ADC) ou Análise de Discurso Textualmente Orientada (ADTO) e da Gramática Visual (GV). 
Em relação à língua inglesa, destacamos, a princípio, que, neste início de século, temos visto uma série de transformações de alcance global nas esferas social, econômica e demográfica no que tange ao uso desse idioma. $\mathrm{O}$ avanço da economia global tem resultado em relacionamentos competitivos, como reflexo da disponibilidade das comunicações modernas e das tecnologias que se intercambiam entre diversas partes do mundo.

Em razão desse fenômeno linguístico, Crystal (1997; 2005) diz ser difícil prever, com exatidão, o que virá a acontecer com essa língua no futuro, mas antecipa que, em virtude do que estamos vendo atualmente, haverá um processo de "desapropriação" linguística do inglês. Dentro dessa mesma perspectiva, Hesman (2000, p. 3) explica que, em decorrência dessa condição o inglês está

[...] se distanciando de suas conotações culturais e políticas na medida em que cada vez mais pessoas estão percebendo que o inglês não é propriedade apenas de uns poucos países, mas um veículo que é usado globalmente e que conduz a maiores oportunidades. O inglês, nesse sentido, pertence a quem quer que o use para qualquer propósito ou necessidade.

Em virtude dessa internacionalização, o inglês tenderá a um processo de contextualização (Pennycook, 1984). O resultado desse processo será uma apropriação, por parte dos "não-nativos" dessa língua, com vistas a interesses específicos, sem, contudo, abrir mão de seus aspectos particulares, garantindo a preservação identitária dos usuários da língua. Esse inglês não mais poderá ser atrelado a alguns países, os quais costumam ser reconhecidos como donos da língua. A expansão do inglês, como Língua Franca, tem um alcance que fará com que ela vá além do que aconteceu com o Latim, que mesmo com a queda do Império Romano, continua a ocupar lugar de destaque no contexto acadêmico.

A difusão do inglês no mundo favorece a expansão do mercado de ensino-aprendizagem da língua. A fim de auferir lucros, as editoras lançam, todos os anos, uma gama de materiais didáticos, para que esses sejam adotados pelas escolas, principalmente as particulares. Os autores 
de alguns desses livros propõem um aprendizado efetivo da língua, influenciados, principalmente, pela Abordagem Comunicativa, e no caso específico do Brasil, que se coadunem aos PCNs - Língua Estrangeira. A larga utilização de tais recursos didáticos, no entanto, pode implicar não apenas no ensino da língua, mas também no repasse de ideologias que sustentem hegemonicamente interesses de dominação.

\section{A conveniência do material didático para o ensino- aprendizagem de inglês}

A utilização de material didático, previamente elaborado pelas editoras, acontece, conforme aponta Allwright (1981), devido à deficiência que alguns professores têm tanto para preparar quanto para selecionar seu próprio material didático. Huctchinson \& Torres (1994) preferem defender que a principal razão não é a deficiência, mas a conveniência. Para esses autores, o material didático possibilita uma considerável "conveniência, provendo uma estruturação que o sistema de ensino/aprendizagem requer" (p. 317). Crawford (2002: 83) assume que a utilização de um material didático, fornecido por uma determinada editora, não somente provê uma estruturação, mas também

[...] uma previsibilidade que é necessária a fim de que o evento social se torne tolerável aos participantes, além de servir de mapa ou plano para o que se pretende e o que se espera, permitindo, assim, que os participantes vejam onde uma lição se encaixa dentro de um contexto mais amplo do programa linguístico.

A comodidade, provida por essa previsibilidade do material didático, auxilia significativamente a condução das aulas pelos professores. Contudo, em consonância com a falta de formação crítica, o material didático pode acabar ditando as regras, ou melhor, a abordagem de como a língua deva ser ensinada. Por essa razão, não se pode descartar a análise do material didático, haja vista o papel que esse exerce na condução das aulas dos professores de línguas. A busca pela comodidade não pode justificar a escolha de materiais didáticos, 
é preciso também atentar para outros aspectos tais como os interesses hegemônicos (Gramsci, 1988; 1995) e a ideologia (Thompson, 1995), na medida em que posicionam sujeitos identitariamente (Castells, 1999) nas relações desiguais de poder (Fairclough, 2001).

Para realizar esse tipo de análise, recorremos à proposta de Fairclough (2001), um dos proponentes da Análise de Discurso Crítica (ADC), que atrela, ao mesmo tempo, as dimensões sociais às análises textuais. Para tanto, ele parte das contribuições de vários teóricos, dentre eles: Bourdieu e Foucault. Para dar conta dos aspectos textuais, nos fundamentaremos na Gramática Sistêmico-Funcional, de Halliday (1985). Por causa dessa ênfase nos estudos discursivos através do texto, a Análise do Discurso Crítica é também denominada de Análise do Discurso Textualmente Orientada (ADTO). Fairclough (2001: 99,100) explica que

A prática discursiva manifesta-se em forma linguística, na forma do que referirei como 'textos', usando 'texto' no sentido amplo de Halliday, linguagem falada e escrita (Halliday, 1978). A prática social (política, ideológica, etc.) é uma dimensão do evento discursivo, da mesma forma que o texto [...] A análise de um discurso particular como exemplo de prática discursiva focaliza os processo de produção, distribuição e consumo textual. [...] A prática social como alguma coisa que as pessoas produzem ativamente e entendem com base em procedimentos de senso comum partilhados (...) as práticas dos membros são moldadas, de forma inconsciente, por estruturas sociais, relações de poder e pela natureza da prática social em que estão envolvidos, cujos delimitadores vão sempre além da produção de sentidos.

Para explicitar a relação entre essas três dimensões, Fairclough (2001), destaca que o procedimento que trata da análise textual pode ser denominada de 'descrição', e as partes que tratam da análise da prática discursiva e da análise da prática social da qual o discurso faz parte de 'interpretação'. Na análise da prática social dois conceitos são bastante caros: 1) ideologia - baseado em Thompson (1995), é inerentemente negativo, pois essa é, por natureza, hegemônica, já que se encontra a serviço do estabelecimento e da sustentação das relações de poder (dominação), com vistas à reprodução da ordem social e o 
favorecimento de grupos dominantes; e 2) hegemonia - baseado em Gramsci (1988) - como domínio exercido pelo poder de um grupo sobre os demais, baseado no consenso.

$\mathrm{Na}$ análise textual, a ADC assume que "os textos são feitos de formas às quais a prática discursiva perpassada, condensada em convenções, dotada de significado potencial" (Fairclough, 2001: 103). Para tanto os itens considerados nessa análise são: vocabulário, gramática, coesão e estrutura textual. O vocabulário é analisado através da lexicalização, isto é, dos processos de significação das palavras no mundo. O sentido da palavra entra na disputa dentro de embates mais amplos. No que tange à gramática, os elementos principais da oração (sintagmas) estão relacionados à transitividade. Os falantes/escritores fazem escolhas quanto ao modelo estrutural das orações.

Fairclough (2003) amplia os postulados teóricos da ADC, propondo uma articulação entre três aspectos: gêneros, discurso e estilo. Os gêneros constituem "o aspecto especificamente discursivo de maneiras de ação e interação no decorrer dos eventos sociais” (p. 65). Eles funcionam como mecanismo articulatório que controla o que pode ser dito a fim de regular o discurso. $\mathrm{O}$ discurso é a representação dos atores sociais nos textos através de posicionamentos ideológicos em relação a eles e suas atividades. O estilo identifica os atores sociais nos textos através dos pressupostos, modalidades (objetivas e subjetivas), as metáforas (conceituais, orientacionais e ontológicas).

A integração desses três significados: acional (gêneros), representacional (discursivo) e estilístico (identificacional) é dialética. Eles somente podem ser subdivididos para efeito explicativo. Os discursos são realizados em gêneros e consolidados através de estilos. As ações e identidades, por sua vez, são discursivamente representadas. A fim de orientar as análises discursivas em uma perspectiva crítica, Fairclough (2003) sugere as seguintes perguntas: 1) gênero - o texto está situado em que cadeia de gênero? Existe uma mesclagem de gêneros? Quais são as características dos gêneros apresentados?; 2) discurso - quais traços caracterizam o discurso (relações semânticas entre as palavras, colocações, metáforas, pressuposições, traços gramaticais); e 3) estilo - como os autores se envolvem em relação 
à verdade (modalidades epístêmicas), obrigações e necessidades (modalidades deônticas).

No Brasil, os estudos da ADC têm contribuído significativamente para a interpretação de práticas sociais desempoderadoras. As publicações desses últimos anos têm favorecido a difusão de pesquisas em várias universidades do País. Entre os estudos da ADC destacamos os de Magalhães (1986; 2000), que nortearam várias pesquisas acadêmicas, principalmente no contexto da Universidade de Brasília (UnB). Artigos e livros de divulgação estão sendo publicados, somente nesses últimos anos, resultantes de investigações de tese de doutorado, foram lançados: Resende \& Ramalho (2006), Resende (2009) e Ramalho e Resende (2011). A tradução de Fairclough (2001) para o português tem auxiliado aqueles que desejam conhecer os fundamentos da ADC, mas que ainda não têm proficiência na leitura em língua inglesa.

\section{Fundamentos teóricos para a análise de imagens}

Os materiais didáticos para o ensino-aprendizagem do inglês se utilizam de recursos multimodais, imagens multicores que ilustram os textos. Para fazê-lo, recorremos a um pressuposto que dê conta de tais recursos. A Gramática Visual, elaborada por Kress e van Leewen (2006) contribui para identificar sistematicamente as estruturas visuais e seus códigos semióticos. A proposta desses teóricos é descrever as imagens partindo do pressuposto de que os seus elementos internos são combinados entre si para comunicar um "todo coerente" para expressar significados distintos. A análise das estruturas visuais pode incluir pessoas, lugares ou objetos na forma de participantes representados e podem estar organizadas em diferentes níveis de complexidade.

A teoria da Gramática Visual se baseia nas metafunções de Halliday (1994), com as devidas adaptações, assim, as metafunções visuais são: representacionais (ideacionais), interativas (interpessoais) e composicionais (textuais). A metafunção representacional diz respeito à relação estabelecida entre os participantes internos de 
uma composição de imagem. Isso porque a imagem é realizada por elementos denominados vetores, os quais correspondem à categoria de ação na linguagem verbal (processos). Os participantes podem ser categorizados em dois tipos: 1) participantes interativos - aqueles que falam, ouvem ou escrevem e lêem, produzem imagens ou as visualizam ou 2) participantes representados, aqueles que são o sujeito da comunicação, ou seja, as pessoas, lugares ou coisas representadas na ou pela fala, ou escrita, ou imagem, os participantes sobre os quais falamos ou escrevemos ou produzimos imagens.

As relações vetoriais que conectam os participantes visuais em uma dada composição podem ser expressas tanto por processos narrativos quanto conceituais. Os processos narrativos representam os participantes visuais em movimentos de ação, em termos de feitos e acontecimentos dinâmicos. Esses participantes podem ser chamados de: Ator/Reator e Meta/Fenômeno; Dizente e Anunciado; ou de Experienciador e Fenômeno. Os processos de ação geralmente incluem tanto um Ator quanto uma Meta, ligados por meio de um vetor - expresso comumente por uma linha diagonal de nível ocular, estabelecida pela direção do contato entre os seus participantes. Quando isso ocorre, declaramos ser uma estrutura transacional, o que significa dizer que ela retrata uma ação ocorrendo entre duas partes. As imagens transacionais podem ou não incluir vetores bidirecionais, que ocorrem quando os participantes alternam-se nos papeis de Atos e Meta. Se a ação envolve apenas o Ator, então, dizemos que se trata de uma imagem não transacional.

Se uma ação executada por um participante envolve o seu olhar em direção a alguém ou alguma coisa, esse processo é denominado de reação, ao invés de ação, o participante que olha é denominado Reator, ao invés de Ator, e o objeto de seu olhar é chamado de Fenômeno, ao invés de Meta. Seguindo esse princípio, se um dado participante olha para alguém ou alguma coisa não claramente especificada ou visualizada na composição, dizemos que se trata de uma reação não transacional. Além de ação e reação, os processos narrativos também podem ser categorizados entre verbais e mentais. Os verbais são representados por balões de fala e pensamento, em que os Atores 
são classificados como Dizentes e Experienciador, aquele que sente e expressa visualmente seu pensamento ou como Fenômeno.

As representações narrativas também são classificadas pelas circunstâncias, ou pelo contexto no qual o participante está inserido e seus complementos, tais como artefatos, ferramentas e as figuras secundárias que complementam os significados das imagens. As circunstâncias de uma imagem podem ser categorizadas em: circunstância de locação - que situa os participantes em termos de plano de fundo da imagem, escolha, intensidade e contraste de cores, nível de detalhes, sobreposição de elementos; circunstância de meio - relacionados ao uso de objetos discretos, artefatos e ferramentas; e circunstâncias de acompanhamento - referente à forma como se estabelece a conexão entre os participantes de uma imagem, não por meio de relações vetoriais, mas por meio de atributos usados para descrever suas características.

Os processos conceituais, por sua vez, representam os participantes de maneira estática, já que esses não possuem ações expressas por vetores. Os processos conceituais, na linguagem verbal, se referem aos processos relacionais e existenciais, uma vez que, conforme explicita Kress e Van Leeuwen (2006: 114) "representam o mundo em seu estado mais ou menos permanente de afazeres e verdades". As estruturas conceituais simbólicas estabelecem a identidade do participante visual através de atributos proeminentes tais como tamanho, escolha das cores, dos posicionamentos, dos usos da iluminação. A partir de tais premissas, Kress e van Leeuwen (2006) estabelecem dois tipos de processos conceituais: 1) atributivo - o participante é salientado por meio de seu posicionamento dentro da imagem, tamanho exagerado, iluminação, nível de detalhamento, foco, tonalidade e/ou intensidade da cor; 2) sugestivo - o significado simbólico resulta do próprio portador.

As estruturas conceituais analíticas se caracterizam por relacionarem o todo com o portador e as partes com atributos possessivos. Para efeito de classificação, Kress e van Leeuwen (2006) consideram: 1) estruturadas - quando apresentam rótulos ou descrições sobre suas partes; e 2) desestruturadas - quando não especificam a relação entre 
as partes e o todo. A classificação das Estruturas Visuais ainda pode ser: 1) exaustivas - quando toda a imagem mostrando o Portador é tomada por suas partes e/ou atributos; ou 2) inclusiva - quando os atributos possessivos são mostrados, mas a maior parte do Portador não aparece. As estruturas conceituais ocorrem por meio de encaixamentos, através dos diferentes níveis de subordinação que estabelecem as relações intrínsecas de interdependência dos elementos de uma imagem.

No que tange à metafunção interativa, Kress e Van Leeuwen (2006) indicam que aspectos como contato, distância social, perspectiva e modalidade têm papel fundamental na identificação da relação entre leitor/observador da imagem e a imagem propriamente dita. O contato é representado quando o participante olha diretamente nos olhos do leitor/ observador, estabelecendo um contato de demanda, convidando o leitor /observador para participar da interação, olhando-o de forma sedutora, agressiva ou imperativa. Mas se o participante não olha diretamente nos olhos do leitor/observador, ocorre um contato de oferta.

Para a análise interacional, uma categoria relevante é a Distância Social. Quando os participantes são retratados em close-up ou plano fechado, cada detalhe de seu rosto e de sua expressão facial é captado, auxiliando, assim, a identificação de traços da sua personalidade. Esse plano abrange o enquadramento, que vai da cabeça até os ombros do participante representado. Diferentemente de quando o participante é apresentado em long-shot ou plano aberto, que contribui para representar os participantes de uma dada composição visual de forma distanciada, mostrando todo o corpo. Há ainda um plano intermediário, que é o medium shot ou plano médio que representa o participante até a cintura ou o joelho, indicando que a sua relação com o leitor é do tipo social.

Em relação ao ponto de vista ou perspectiva, Kress e Van Leeuwen (2006) consideram os ângulos frontais, oblíquos e verticais. A utilização do ângulo frontal está associada à atitude de um envolvimento entre o leitor/observador e o participante. O ângulo oblíquo conduz a um sentido de desligamento ao apresentar o participante em perfil, deixando subentendido que a representação não pertence ao nosso mundo. O ângulo vertical e suas variantes (alto, 
baixo ou de nível ocular) apontam para as diversas relações de poder representadas entre o participante e o leitor/observador.

A modalidade ou valor de realidade é representado por meio da modalidade naturalista ou sensorial. A modalidade naturalista se concretiza através da congruência que existe entre o objeto de uma imagem e aquilo que se percebe pelo olho naturalmente. Assim, quanto maior for a correspondência entre a imagem e o real, maior será a modalidade da imagem. Kress e van Leeuwen (2006) ressaltam que as imagens naturalistas geralmente possuem: 1) alta saturação de cores, no lugar de preto e branco; 2) cores diversificadas, ao invés de cores monocromáticas; e 3) cores moduladas. Eles atentam também para a contextualização da imagem, seu pano de fundo. A modalidade sensorial evoca sentimentos mais subjetivos no leitor/observador, ocorrendo uma diminuição da modalidade naturalista.

Em relação à metafunção composicional, cabe a essa integrar os elementos visuais das outras metafunções a fim de constituir um todo coerente. Para tanto, envolve o valor da informação, que se refere à disposição dos elementos dentro da composição visual, disponibilizados nas seguintes dicotomias da zona pictográfica: esquerda/direita; topo/ base; centro/margem. Para Kress e van Leeuwen (2006), o lado direito da imagem geralmente contem a informação chave, para qual o leitor/observador presta maior atenção, já que nela se apresenta o elemento novo. No lado esquerdo se encontra o elemento dado, previamente conhecido pelo leitor/observador, com o qual tem alguma familiaridade. Por isso, em informes, o texto verbal costuma ser posto no espaço esquerdo e o visual à direita.

O posicionamento no topo e na base da imagem apresenta traços distintos. A colocação de tais elementos na parte superior expressa a informação ideal, a essência idealizada e generalizada, a promessa do produto, o que evoca os sentidos emotivos no intuito de expressar o que produto pode ser e não o que ele é. Ao elemento na base da imagem, por oposição, cabe a solicitação das informações a respeito do produto. Quando o posicionamento se encontra na parte central e marginal, há uma predominância de certos elementos na imagem ou a ausência dela, isso acontece nos casos de elementos subordinados 
a uma imagem central, colocados em posição hierárquica inferior em relação à informação nuclear.

Outro elemento composicional é a saliência que se refere à ênfase dada aos elementos visuais a fim de torná-los mais preponderantes do que outros. A disposição de um elemento em primeiro plano ou em plano de fundo, seu tamanho, contrastes de cores podem reforçar ou diminuir o grau de saliência, na medida em que criam uma identificação do participante principal representado na imagem. Além do valor da informação, saliência, a Estruturação é um elemento composicional também relevante. De acordo com Kress e van Leeuwen (2006), essa relação é formada a cada vez que as conjunturas que marcam as unidades diferentes dos textos visuais estão ausentes. As imagens contem uma estruturação fraca quando os elementos interligados em um fluxo contínuo, por meio de cores e formas semelhantes, vetores conectivos evoca um sentido de identidade de grupo.

\section{Aspectos teórico-metodológicos}

\subsection{Abordagem da pesquisa}

Esta pesquisa parte de uma visão científica de crítica social motivada pelo objetivo de prover base investigativa para um questionamento crítico da vida social em termos políticos e morais, ou seja, em termos de justiça social e de poder (Fairclough, 2003). Para tanto, conforme destacam Resende e Ramalho (2006), trata-se de um enquadramento no campo da pesquisa social crítica, resultante da teoria, análise lingüística e semiótica, que auxiliam a prática interpretativa e explanatória tanto a respeito dos constrangimentos sociais sobre o texto como de efeitos sociais desencadeados por sentidos de textos. A esse respeito, Chouliaraki e Fairclough (1999) operacionalizam conceitos de teorias sociais crítica sobre práticas sociais característica da modernidade tardia, com vistas à pesquisa da vida social que favoreça a superação de relações de dominação. 


\subsection{Metodologia da pesquisa}

A pesquisa aqui empreendida perseguiu algumas etapas: 1) identificação das cinco principais escolas particulares de uma determinada cidade; 2) coleta de dez textos de materiais didáticos utilizados pelos professores do Ensino Médio dessas escolas; 3) análise prévia dos textos didáticos a fim de identificar aspectos ideológicohegemônicos no material; 4) análise de aspectos ideológicos identificados nos textos dos materiais didáticos; 5) identificação de marcas lingüístico-ideológicas nos textos: lexicais, gramaticais e textuais nos materiais didáticos; e 6) análise dos recursos visuais (multimodais) apresentados no material didático e sua relação com os textos analisados. Em virtude da limitação de espaço, apresentaremos, neste artigo, apenas dois dos mais representativos textos analisados.

\section{Análise de textos didáticos}

\subsection{Texto 1}

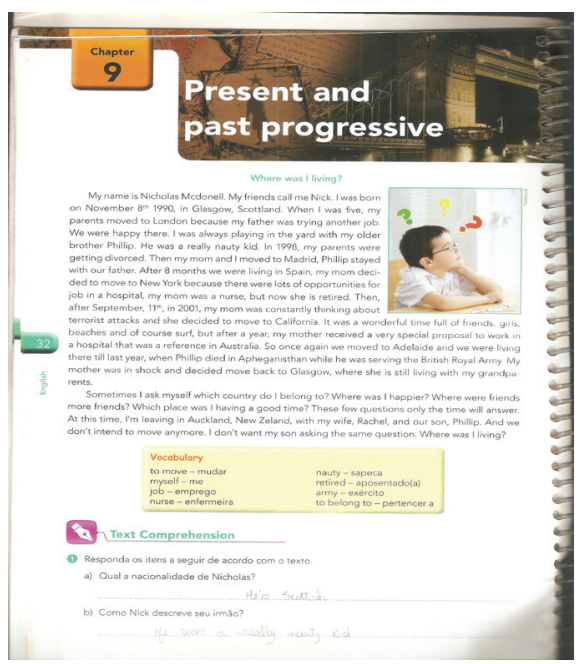




\section{Apresentação do Texto 1}

O texto 1, no capítulo 9 do livro didático, tem como objetivo trabalhar a estrutura gramatical present and past progressive. A fim de atender a essa meta, o suposto autor do texto, Nicolas Mcdonell, o intitula com uma pergunta: where was I living? Esse autor tenta, a partir dessa indagação, mostrar que tem dificuldade de identificar-se geograficamente, já que, ao longo da sua vida, morou em Londres, Madrid, Nova Iorque, Austrália e Nova Zelândia. Diante de tantas mudanças, o autor se pergunta: which country do I belong to?

\section{Ação: o gênero textual}

O texto apresenta característica do gênero depoimento pessoal. Ele começa pela apresentação: My name is Nicolas Mcdonell. My friends call me Nick. A intenção comunicativa do autor do texto é apresentar um relato da sua história: When I was five my parents moved to London. O texto, ainda que seja didático, evoca um padrão reconhecível pelos alunos, na medida em que narra, em detalhes, as experiências que vivenciou desde o seu nascimento, as mudanças dos pais em virtude de trabalho e divórcio. Ao concluir o texto, há um apelo moral: I don't want my son asking the same question.

\section{Discurso: representações sociais}

O autor do texto assume que mudanças geográficas são normais, principalmente quando se trata de busca por melhorias de trabalho, uma mudança para Nova Iorque se fez necessária, já que naquela cidade existiam lots of opportunities for job. Depois a mãe precisou se mudar para a Austrália, em virtude de a very special proposal to work in a hospital. $\mathrm{O}$ autor do texto reconhece que as pessoas tomam decisões na vida com motivações socioeconômicas. Essas determinam as opções de onde os indivíduos devam morar, elas controlam os relacionamentos pessoais. Seus pais se divorciaram quando ele tinha pouca idade, e como resultado, ele e seu irmão, Phillip, acabaram distanciados.

Essa é uma dura realidade com a qual as pessoas no contexto da modernidade tardia (Giddens, 1991), e, conforme exposta no 
texto, tende a ser naturalizada. A mãe do menino é apresentada como uma mulher ambiciosa, que não se satisfaz com pouco e quer sempre mais. As mudanças geográficas não aconteceram apenas para obter melhores "condições de vida", mas também em decorrência dos terrorist attacks, justamente o que fez com que sua mãe se mudasse para a Califórnia. Os líderes mulçumanos são representados no texto como vilões, o autor reproduz a ideologia ocidentalizada americana de demonização da religiosidade palestina, denominado-os de "terroristas", diferentemente do reconhecimento que esses têm na cultura do oriente médio.

\section{Estilo: identidade}

O autor do texto se identifica como membro de uma família capitalista. Os membros da família não podem perder oportunidade. A mãe, uma enfermeira, não desperdiça oportunidade de adquirir empregos lucrativos. O próprio Nicolas Mcnonell, diferentemente da maioria dos jovens, passou por experiências consideradas normais para alguém da classe média. Quando morou na Califórnia, diz ele: it was a wonderful time full of friends, girls, beaches and of course surf. $\mathrm{O}$ autor do texto se identifica como homem, figurando o macho que está sempre "rodeado de girls". Mesmo os friends podem ser descartados, eles tão somente fazem parte de um wonderful time. Decorridos os anos, por causa das andanças por diversos países, o autor do texto mostra-se deslocado, e se pergunta: which country do I belong to?. Essa pergunta é apenas uma de uma série, que, ao final, faz o autor do texto avaliar que tudo isso foi negativo, diz ele: I don't want my son asking the same question. $\mathrm{O}$ autor pretende romper com essa prática, pois não quer ver seu filho fazendo esse mesmo tipo de pergunta.

\section{A imagem do texto}

A imagem do texto apresenta uma criança - participante sozinha sem um objeto direto de interação. Ainda que haja um jogo, tipo quebra-cabeça, sobre a mesa na qual a criança mantém um dos braços, ela não direciona o olhar para o brinquedo. A mão esquerda 
está elevada à orelha, há uma nítida demonstração de monotonia. A foto naturalista mostra a criança quase em perfil, em oferta, sem olhar diretamente para o observador, e em plano aberto, apenas da cintura para cima. A cortina da janela, ao fundo, é branca, representando opacidade, reforçando a falta de dinamismo. Existem três sinais de interrogação sobre a cabeça da criança, cada uma delas de uma cor: verde, amarelo e vermelho. Eles apontam para indagações da criança a respeito da sua identidade. Ele não sabe o que esperar, a única certeza parece ser a incerteza. As diferentes cores dos sinais (saliência) demonstram a necessidade de o garoto romper com aquela condição. As mudanças repentinas fizeram com que ele se encontrasse sozinho. A disposição dos objetos identifica a condição social do menino: cor branca, óculos novos, e roupa bem alinhada, em consonância com a arrumação do ambiente. Essas características revelam o pertencimento da criança a uma família de condição financeira compatível com os interesses econômicos atribuídos à mãe, já que essa é identificada como a mulher que toma as decisões, ainda que, para tanto, sacrifique os relacionamentos familiares em prol dos interesses econômicos.

\subsection{Texto 2}

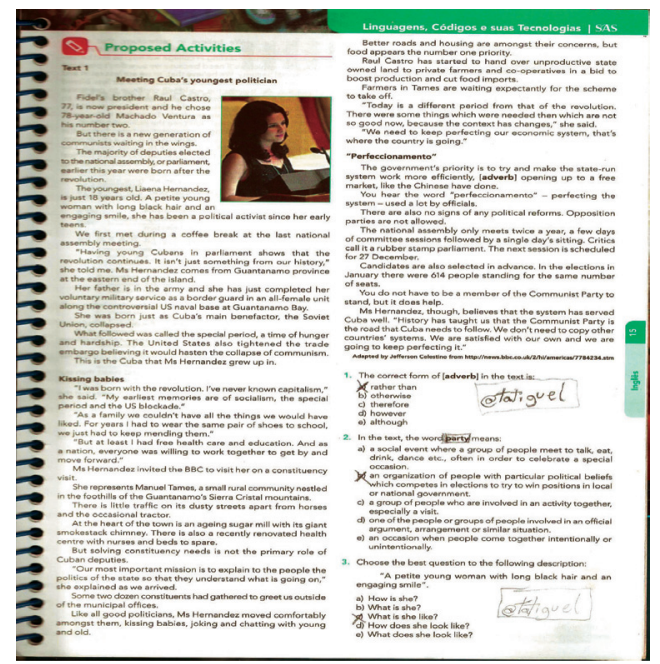




\section{Apresentação do Texto 2}

O texto intitulado Meeting Cuba's youngest politician (apresentando a mais jovem política de Cuba) foi publicado originalmente no site da $\mathrm{BBC}$ e posteriormente adaptado para o material didático. $\mathrm{O}$ 'autor' discorre a respeito da atuação política em Cuba de Lisena Hernandez, uma jovem cubana de 18 anos de idade. Enquanto recurso didático, a proposta do texto é o ensino-aprendizagem dos advérbios em inglês, por esse motivo, encontramos, ao longo do texto, advérbios como recently, confortably, expectantly e efficiently. A identificação dos advérbios no texto apresenta enfoque comunicativo, na medida em que as perguntas são colocadas contextualmente, com vistas à identificação de informações no texto sobre a jovem Hernandez. Mas carece de análise crítica sobre o modo o autor-jornalista avalia a política cubana, assumindo não apenas a posição de jornalista, mas de instrutor no livro didático.

\section{Ação: o gênero textual}

O gênero didático situado é, primariamente, texto para ensinoaprendizagem de línguas, mas em consonância com os textos que circulam na sociedade, e na tentativa de trazê-los à esfera escolar, identificamos características do gênero reportagem/entrevista jornalística. Como o texto foi adaptado da BBC, permanecem traços desse gênero desencaixado. $\mathrm{O}$ autor desenvolve seu texto a partir das respostas de Ms. Hernandes, e, ao mesmo tempo, se coloca em relação aos seus posicionamentos. Ao final, o autor-jornalista apresenta a fonte de onde foi extraído o texto, relacionando-o com o contexto jornalístico. A intenção comunicativa do autor é destacar que existem políticos comunistas jovens em Cuba, e que esses pretendem levar o sistema adiante, mas com as devidas adaptações à sociedade contemporânea, ou mais precisamente, capitalista.

\section{Discurso: representações sociais}

O texto é iniciado com a seguinte declaração: Fidel's brother, Raul Castro (76), is now president and he chose 78-year-old Machado 
Ventura as his number two. A identificação das idades de Raul Castro e Machado Ventura, nos textos, apontam para um contraste, e ao mesmo, confronto, entre velhice e novidade. Esses "velhos" políticos cubanos representam o que há de retrógrado e ultrapassado no sistema comunista. Essa idéia é reforçada pela presença da conjunção adversativa but, que aponta para uma oposição logo em seguida. $\mathrm{O}$ autor assegura categoricamente: but there is a new generation of communists waiting in the wings. O entrevistador assume, ao longo do texto, que o comunismo cubano carece de transformação, que não dá mais conta das necessidades econômicas atuais, inclusive do povo cubano. O texto em foco foi publicado em um jornal de tendência neocapitalista, demarcando, assim, o posicionamento ideológico e hegemônico das avaliações feitas em relação ao comunismo. Desde a queda do Muro de Berlim e das mudanças pelas quais passou a exUnião Soviética, há um interesse capitalista de que Cuba, remanescente do bloco socialista, seja reestruturado, a fim de atender aos interesses de uma suposta globalização (GIDDENS, 1989).

\section{Estilo: identidade}

$\mathrm{O}$ autor do texto mostra que teve contato direto com a jovem comunista cubana, e contextualiza a situação, a fim de ressaltar sua autoridade diante das afirmações: We first met during a coffee break at the last national assembly meeting. $\mathrm{O}$ encontro acontece em uma ocasião informal, mas no contexto de uma assembléia nacional do partido comunista. Esse foi apenas um dos encontros, o jornalista fala em first met, a fim de mostrar que teve outras oportunidades de conversar com a jovem política, a quem chama de Ms. Hernandez, contrapondo, ao mesmo tempo, a proximidade da conversa com o distanciamento do cargo político da jovem. $\mathrm{O}$ autor-jornalista descreve a queda da União Soviética e o embargo econômico americano a Cuba, e, ao final, é categórico, inclusive na opção dos processos: This is the Cuba that Ms. Hernandez grew up in.

Ao avaliar a defesa da jovem política sobre as contribuições do comunismo em Cuba, diz Ms. Hernandez, though, believes that the system has served Cuba well. O autor não assume o mesmo, por isso, 
modaliza e não se identifica com a defesa de Ms. Hernandes believes que o sistema serviu bem a Cuba. Ao avaliar o sistema político de Cuba, o autor-jornalista cita o uso freqüente do termo 'perfeccionamento', a fim de aproximar as informações na língua falada em Cuba, espanhol, com o interesse dos jovens comunistas de aperfeiçoar o sistema. Em seguida avalia essa possibilidade, assumindo que There are no signs of any political reforms. Opposition parties are not allowed, em seguida afirma categoricamente que as eleições naquele país não têm valor, já que os Candidates are also selected in advance. Os marcadores adverbiais no texto, ainda que pretendam ser utilizados como recursos didáticos, reforçam o posicionamento político do autor. Na expressão: The government's priority is to try and make the state-run system work more efficiently. $\mathrm{O}$ autor avalia que o sistema estatal de governo não funciona eficientemente e que melhorá-lo é uma prioridade dos jovens comunistas.

\section{A imagem do texto}

$\mathrm{Na}$ imagem relacionado ao texto Meeting Cuba's youngest politician, Ms. Hernandez é representada como uma figura proeminente, posicionada conceitualmente diante de um microfone, no contexto de uma assembléia política. A participante representada não olha diretamente nos olhos do observador, ela então "se oferece" como objeto de contemplação. A forma como Ms. Hernandez é perspectivada aponta para uma condição de incerteza em relação ao futuro, de expectativa sobre o que virá adiante. $\mathrm{O}$ distanciamento social é apresentado em nível intermediário, em plano médio, retratada apenas da cintura para cima. $\mathrm{O}$ ângulo ou perspectiva é oblíquo, isso porque, na imagem se evoca um sentido de desligamento, ressaltando que o mundo da Ms. Hernandez é uma outra realidade (Kress \& Van Leeuwen, 2006), distante do contexto capitalista.

A interação da jovem com os demais membros da assembléia é inferida, já que esses não se encontram presentes. Essa elipse evoca o que fora dito no texto, que os políticos cubanos são de "fachada", já que são escolhidos previamente, sem que o povo possa de fato decidir pelos seus representantes. A participante é posicionada na imagem em 
nível inferior ao ocular, ressaltando uma relação de poder assimétrica, a partir do foco do observador, em nível superior de poder. O olhar capitalista sobre o comunismo costuma ser de superioridade, principalmente nesses últimos anos, depois da queda do bloco soviético e do Muro de Berlim. Em termos de estrutura composicional, a participante está posicionada no espaço esquerdo, sendo esse o tema da imagem, o ambiente parlamentar é o rema, o primeiro é saliente em relação ao último, que aponta para os "velhos" políticos cubanos, ausentes na imagem, por representarem o ultrapassado, dentro do modelo capitalista, o descartável e desnecessário.

\section{Considerações finais}

A análise dos textos didáticos demonstra a permanência de determinadas práticas sociais que são sustentadas ideologicamente através da prática discursiva. Nos textos escolhidos para este artigo, observamos que circulam, em contextos escolares, discursos que fomentam posicionamentos desempoderadores, dentre elas, sobre a questão palestina e o comunismo. Os líderes palestinos são rotulados de 'terroristas', como geralmente acontece na mídia ocidental americana, investido por discursos imperialistas, há uma demonização dos palestinos. Por outro lado, o consumismo é normalmente estimulado em textos didáticos, os quais, com a proposta de trazerem gêneros da propaganda, incitam a aquisição desenfreada de produtos e mercadorias.

Mesmo com as mudanças experimentadas pela sociedade contemporânea, principalmente na América Latina, permanece a política de execração a essa forma de governo, reproduzida em textos didáticos. Com fundamentação no capitalismo, há textos que se posicionam negativamente em relação ao comunismo, e também à velhice, na medida em que associa a idade dos seus principais líderes à defasagem do sistema comunista cubano, considerando-o antiquado e desnecessário. As imagens dispostas nos textos reforçam essas representações da sociedade, um menino, filho de mãe capitalista, que não consegue saber quem é, vítima dos anseios maternos de 
acumular riquezas. A jovem comunista, também procura encontrarse identitariamente, na tentativa de "aperfeiçoar" um modelo "ultrapassado", que não satisfaz aos interesses do neoliberalismo econômico.

Recebido em: 13/08/2011 Aprovado em: 27/09/2011 jotaroberto@uol.com.br

\section{Referências bibliográficas}

ALLWRIGHT, R. L. What do we want teaching materials for? ELT Journal, 36 (1), 1981.

CASTELlS, M. O poder da identidade. 3 ed. São Paulo: Paz e Terra, 1999. (Trad. de Klauss Brandini Gerhardt).

CHOULIARAKI, L.; FAIRCLOUGH, N. Discourse in late modernity. Edinbugh: Edinburg University Press, 1999.

CRAWFORD, J. The role of materials in language classroom: finding the balance. In: RICHARDS, J. C., RENANDYA, W. A. (eds.) Methodology in language teaching. Cambridge: Cambridge University Press, 2002.

CRYSTAL, D. A revolução da linguagem. Rio de Janeiro: Zahar, 2005.

CRYSTAL, D. English as a global language. Cambridge: Cambridge University Press, 1997.

FAIRCLOUGH, N. Analyzing discourse: textual analysis for social research. London: Routledge, 2003.

FAIRCLOUGH, N. Discurso e mudança social. Brasília: Editora UNB, 2001. GIDDENS, A. A constituição da sociedade. São Paulo: Martins Fontes, 1989.

GRAMSCI, A. A Gramsci Reader: selected writings 1916-1935. FORGACS. D. (Org.) London: Lawrence and Wishart, 1988.

GRAMSCI, A. Concepção dialética da história. Rio de Janeiro: Civilização Brasileira, 1995. 
HALLIDAY, M. A. K. An introduction to functional grammar. $3^{\text {rd }}$ ed. London: Hodder Arnold, 2004.

HALLIDAY, M. A. K. An introduction to Functional Grammar. London: British Library Cataloguinte in Publication Data, 1994

HALLIDAY, M. A. K. Language as social semiotic. Edward Arnold. London, 1978.

HESMAN, M. The role of English in the $21^{\text {st }}$ century. FORUM. 38/1 (2-6), 2000.

HUTCHINGSON, T.; TORRES, E. The textbook as agent of change. ELT Journal, 48(4), 1994.

KRESS, G.; VAN LEEWEN, T. Reading images: the grammar of visual design. London: Routledge, 2006.

LACOSTE, Y.; RAJAGOPALAN, K. (org.) A geopolítica do inglês: Parábola, 2005.

MAGALHÃES, I. Eu e tu: a construção do sujeito no discurso médico. Brasília. Thesaurus, 2000.

MAGALHÃES, I. Por uma abordagem crítica e explanatória do discurso. D.E.L.T.A, 2(2), 1986, p. 181-215.

RAJAGOPALAN, K. Por uma lingüística crítica. São Paulo: Parábola, 2003.

RAMALHO, V.; RESENDE, V. de M. Análise de discurso (para a) crítica: o texto como material de pesquisa. Campinas, SP: Pontes Editores, 2011.

RESENDE, V. M. Análise de discurso crítico e realismo crítico: implicações interdisciplinares. Campinas, SP: Pontes Editores, 2009.

RESENDE, V. M.; RAMALHO, V. Análise de discurso crítica. São Paulo: Contexto, 2006.

THOMPSON, J. B. Ideologia e cultura moderna. Petrópolis: Vozes, 1995. 